\title{
Ética e Mercado: uma análise comparativa das propostas morais de Sandel e de Walzer
}

\author{
Ethics and Market: a comparative analysis of the \\ moral proposals of Sandel and Walzer
}

\author{
Marcello Ciotola ${ }^{l}$ \\ Gustavo França ${ }^{2}$
}

\begin{abstract}
RESUMO
Este artigo pretende tratar do tema da moralidade das atividades econômicas e dos limites morais do mercado, a partir de uma comparação entre as propostas de dois filósofos norteamericanos contemporâneos: Michael Sandel (1953-) e Michael Walzer (1935-). Faremos notar que ambos os autores chegam a uma resposta semelhante para o problema (o mercado não é um instrumento mau em si mesmo, mas sua presença deve se restringir aos bens sociais afeitos à sua lógica distributiva, sem invadir os âmbitos próprios de outras lógicas de justiça), porém, partindo de fundamentos substancialmente distintos - o primeiro filia-se ao comunitarismo aristotélico e defende que os bens têm uma natureza objetiva, identificada por sua finalidade; o segundo é adepto do chamado multiculturalismo e entende que os bens são criados e definidos pela cultura de sociedades específicas.
\end{abstract}

PALAVRAS-CHAVE: Ética, mercado, Economia, Sandel, Walzer, bens, justiça distributiva, comunitarismo, multiculturalismo.

\begin{abstract}
This article intends to deal with the theme of the morality of the economic activities and the ethical limitations of the market, based on a comparison between the proposals to face the theme of two contemporary American philosophers: Michael Sandel (1953-) and Michael Walzer (1935-). We will note that both authors arrive at a similar response to the problem (the market is not a bad instrument in itself, but its presence must be restricted to social goods that are tied to its distributive logic, without invading the realms of other sistems of justice), however starting from substantially different foundations - the former is affiliated with Aristotelian communitarianism and argues that goods have an objective nature, identified by

\footnotetext{
${ }^{1}$ Professor de Filosofia do Direito na PUC-Rio e na UERJ. Professor de Ética no programa de pós-graduação em Direito da UNESA. Doutor em Direito pela PUC-Rio.

2 Doutorando em Filosofia pela Universidad de Navarra. Mestre em Filosofia pelo IFCS da UFRJ.
} 
their ends; the second is adept of the so-called multiculturalism and understands that the goods are created and defined by the culture of specific societies.

KEYWORDS: Ethics, market, Economics, Sandel, Walzer, goods, distributive justice, communitarianism, multiculturalism.

\section{INTRODUÇÃO}

Este artigo tem como objetivo analisar o tema dos limites morais do mercado em dois filósofos norte-americanos contemporâneos: Michael Sandel (1953-) e Michael Walzer (1935-).

Enquanto Sandel filia-se, ao lado de Alasdair MacIntyre (1929-), a um comunitarismo que retoma a filosofia clássica, Walzer junta-se a Charles Taylor (1931-) na defesa do chamado comunitarismo multiculturalista, impregnado de relativismo sociológico.

Por um lado, os dois autores possuem traços distintos em sua maneira de conduzir o pensamento. Sandel é famoso por sua abordagem casuística, rica em casos concretos, mas sem a pretensão de dar um tratamento sistemático à matéria. Já Walzer possui uma estruturada teoria da justiça social, na qual encaixa sua análise da ética econômica.

Por outro lado, enquanto Sandel possui uma obra dedicada unicamente à temática, intitulada "O que o dinheiro não compra", Walzer, ao contrário, trata da questão, em "As esferas da justiça"4, como um dos elementos de sua proposta global para a justiça distributiva.

Desse modo, no primeiro tópico do artigo, indicaremos os principais aspectos do referido livro de Sandel, procurando descrever os elementos que compõem a sua compreensão das questões econômicas (notadamente as características que tornam um bem, por natureza, afeito à lógica de mercado, assim como as distorções injustas geradas pela aplicação de tal lógica a bens alheios a si).

Em seguida, estudaremos a teoria das esferas distributivas de Walzer e sua aplicação às trocas no mercado. Examinaremos sua teoria dos bens sociais, seu conceito de esferas da

\footnotetext{
${ }^{3}$ SANDEL, Michael J. O que o dinheiro não compra: os limites morais do mercado. Trad. Clóvis Marques. $-5^{\text {a }}$ ed. - Rio de Janeiro: Civilização Brasileira, 2013.

${ }^{4}$ WALZER, Michael.As Esferas da Justiça. Em Defesa do Pluralismo e da Igualdade, tradução de Nuno Valadas, Lisboa, Presença, 1999.
} 
justiça e, por fim, enumeraremos os objetos sobre os quais é moralmente vedado incidir a lógica do mercado.

\section{A ÉTICA ECONÔMICA EM MICHAEL SANDEL}

O filósofo norte-americano Sandel, de filiação ao comunitarismo aristotélico, trata das questões econômicas, sob a perspectiva da moral, em obra bem ao seu estilo marcadamente casuístico, em que, embora ofereça fundamentos importantes para a elaboração de uma teoria ética econômica, não tem a pretensão de dar um tratamento sistêmico que responda a todas às questões.

O ponto de partida de Sandel é a análise da situação do mundo atual, fortemente caracterizada pelo que se costuma chamar de triunfalismo do mercado. Desde as últimas décadas, com a definitiva derrocada do socialismo, o mecanismo de mercado e suas ideias passaram a gozar de um gigantesco prestígio. Não se trata de uma injustiça: de fato, nenhum sistema econômico na história havia conseguido gerar tanta riqueza, bem-estar e prosperidade ${ }^{5}$.

Entretanto, o sucesso do mercado traz consigo um fenômeno cujo significado precisa ser analisado: a expansão da lógica de mercado a praticamente todas as áreas da vida, muitas das quais tradicionalmente regidas por outras normas sociais. Sandel nos fornece uma fartura de exemplos: escolas, hospitais e prisões inseridos no sistema de lucro; a substituição da segurança pública e até das Forças Armadas na guerra por empresas privadas de segurança e militares; o marketing agressivo de empresas farmacêuticas para a venda de remédios caríssimos; a venda de direitos de apor nome comercial a espaços públicos; a comercialização de material reprodutivo e as famosas "barrigas de aluguel"; a compra e venda por empresas e por países do direito de poluir ${ }^{6}$.

A recente crise financeira levantou o questionamento sobre a decadência moral do sistema de mercado, apontando-se como responsável por ela a ganância. Sandel, porém, não crê que a imposição de freios à cobiça dos empresários, chamando-os, juntamente com os administradores públicos, à responsabilidade social, chegue ao cerne do problema. Em sua

\footnotetext{
${ }^{5}$ Cf. id., ibid., p. 11.

${ }^{6}$ Cf. id., ibid., p. 13.
} 
visão, é preciso refletir sobre a chegada do mercado a esferas da vida humana alheias a ele. Para compreender adequadamente os dilemas que se desenham, urge pensar sobre o lugar moral do mercado na sociedade e seus limites, marcados por outros valores constitutivos do meio comunitário ${ }^{7}$.

Sandel identifica uma guinada recente no pensamento econômico, que pode ser ilustrada por uma comparação entre o principal manual de Economia lido na segunda metade do século XX, de Paul Samuelson (1915-2009), e um dos mais influentes manuais da atualidade, escrito por Gregory Mankiw (1958-). Samuelson restringia a Economia ao estudo do "mundo dos preços, salários, taxas de juros, ações e títulos, bancos e crédito, impostos e gastos". Tratava-se de estudo em busca de princípios que levem ao aumento da produtividade e à melhoria no padrão de vida das pessoas. Mankiw, por sua vez, define a Economia como "simplesmente um grupo de pessoas interagindo na condução de suas vidas". Ou seja, em pouco tempo, a Ciência Econômica passou a ser vista como englobando todo o processo racional de tomada de decisões das pessoas nos diversos âmbitos da vida ${ }^{8}$.

Esse enquadramento de ideias tem, segundo Sandel, sua mais superlativa representação na chamada teoria dos preços implícitos, tão bem estampada na obra do economista Gary Becker (1930-2014). Becker entende que a Economia não é o estudo da produção e distribuição de bens de consumo, mas de todo o comportamento humano. A repetição da visão tradicional deriva de uma relutância em submeter certas áreas da vida ao cálculo econômico. O seu objetivo é vencer essa resistência.

Para ele, o homem sempre age buscando maximizar o seu bem-estar. O tipo de cálculo que faz ao escolher um parceiro não é diferente daquele que realiza na escolha da marca do café. Embora nem sempre tenham consciência disso, o raciocínio dos indivíduo sempre revela indícios de base nos preços implícitos. Becker exemplifica com o casamento e o divórcio: um homem procura casar-se quando a expectativa de utilidade do casamento supera a expectativa de utilidade do celibato, e põe fim ao seu casamento quando a expectativa de utilidade da nova situação supera a perda de utilidade da separação, incluindo o distanciamento dos filhos, a divisão de bens e os custos jurídicos ${ }^{9}$.

Nessa esteira de análise, um desses princípios econômicos que regem a vida é o de que as pessoas reagem a incentivos. Sandel aponta que há autores que chegam a definir a

\footnotetext{
${ }^{7}$ Cf. id., ibid., p. 12 .

${ }^{8}$ Id.. ibid., p. 85.

${ }^{9}$ Apud id., ibid., pp. 51-52.
} 
Economia como o estudo dos incentivos. O professor de Harvard observa que se trata de uma inovação na teoria econômica. Não há qualquer referência a incentivos em Adam Smith (1723-1790) ou em qualquer economista clássico, tornando-se termo da moda apenas nas últimas décadas ${ }^{10}$.

Segundo Sandel, o protagonismo dos incentivos significa um passo além da expansão do mercado a todos os âmbitos da existência. Atribui ao economista um papel ativo na manipulação do funcionamento social. Em contraste com os preços implícitos de Becker, simplesmente artifícios deduzidos do comportamento individual e usados para explicá-lo formalmente, os incentivos são intervenções que o economista ou o gestor público concebe e impõe ao mundo, para atingir objetivos públicos pré-definidos ${ }^{11}$.

Sandel nota bem que os incentivos trazem uma subversão do liberalismo clássico e do conceito smithiano de mão invisível. O mercado deixa de ser uma mão invisível, um fluxo natural das relações sociais, para se tornar uma força bruta interventora, que manipula a vida de todos. Tamanho vulto adquiriu essa tendência - comenta o nosso autor - que um novo vocábulo foi introduzido no cotidiano da língua inglesa: o verbo "incentivizar". "Incentivizar" é definido como estimular alguém por meio de um incentivo. Nos últimos anos, esse verbo se tornou cada vez mais corrente no vocabulário técnico das discussões de política econômica ${ }^{12}$.

Sandel, já iniciando sua discussão crítica dessa visão economicista das coisas, nos apresenta exemplos de falhas dos incentivos. Fala-nos, por exemplo, de um estudo realizado em creches de Israel. Sofrendo com o problema dos atrasos dos pais na hora de buscar os filhos, tais estabelecimentos resolveram estabelecer uma multa para esses atrasos. Ocorre, porém, que, com a medida, eles aumentaram. Isso acontece, segundo a interpretação de Sandel, porque a monetarização alterou a forma como os pais viam a situação. Os pais que antes se atrasavam se sentiam culpados por causar um inconveniente aos professores. Agora, passaram a entender o cuidado dos filhos nos casos de atraso como um serviço oferecido pela creche, sob o pagamento de uma taxa extra ${ }^{13}$.

Esse exemplo já nos mostra que a lógica do mercado tem seus limites e abre espaço para a argumentação de Sandel acerca dos problemas da sua expansão a todas as áreas da existência. $\mathrm{O}$ núcleo dessa argumentação consiste em dois fundamentos. O primeiro e mais

\footnotetext{
${ }^{10}$ Cf. id., ibid., pp. 85-86.

${ }^{11}$ Id. ibid., p. 86.

${ }^{12}$ Cf. id., ibid., pp. 86-87.

${ }^{13}$ Id., ibid., pp. 65-66.
} 
óbvio deles é a geração da desigualdade. Quando tudo passa a estar a venda, a vida torna-se muito mais difícil para os que têm menos recursos. Não parece irrazoável que algumas pessoas tenham mais condições de comprar iates do que outras, mas, quando as condições de pagar quantias mais elevadas se tornam o critério para a distribuição de quaisquer bens incluindo atendimento médico, escolas de qualidade, influência política, dispensa do serviço militar, órgãos - há sérias razões para se questionar a justiça do mecanismo social ${ }^{14}$.

Além disso, certas trocas se revelam iníquas exatamente porque a desigualdade de posições atinge gravemente a verdadeira voluntariedade. Um pobre que vende seu rim para alimentar a família, provavelmente, o faz não por livre vontade, mas por coação das circunstâncias de penúria ${ }^{15}$.

O segundo e mais importante fundamento da análise crítica de Sandel é a corrupção moral dos bens provocada pela lógica de mercado. O que o autor defende é que estipular preços para as coisas não é simplesmente uma forma de distribuí-las, mas também denota um modo específico de encarar aquela realidade. Assim como os pais que, obrigados a pagar pelos seus atrasos, passaram a enxergar sua irresponsabilidade moral como um serviço prestado, as crianças remuneradas por ler livros enxergam a leitura como uma obrigação vantajosa, não como um autêntico prazer intelectual, e os soldados que pagam mercenários para lutar na guerra no seu lugar perdem completamente a noção de cidadania. O mercado altera a natureza dos bens a ele submetidos ${ }^{16}$.

Essa segunda espécie de argumento, insistimos, merece destaque porque traz uma questão nova e mais profunda à equação. A ideia é que cada bem social tem um valor intrínseco próprio, que pode se degradar quando sujeito à compra e venda. Mercantilizar um rim é imoral porque rebaixa a pessoa humana e seu corpo a um preço, recusando-lhes a dignidade com que devem ser tratados. Se o argumento da desigualdade representa uma objeção apenas às condições das trocas mercantis, exigindo sua correção para assegurar a voluntariedade, a crítica da corrupção não se contenta com circunstâncias justas para a troca, mas rechaça esta última sempre que ela, em si, for incompatível com a natureza do bem distribuído. Por essa lógica, mesmo que se possa chegar a um quadro em que a prostituição

\footnotetext{
${ }^{14}$ Cf. id., ibid., p. 14.

${ }^{15}$ Cf. id., ibid., pp.110-111.

${ }^{16}$ Cf. id., ibid., pp. 14-15.
} 
seja integralmente de livre escolha das prostitutas, sua prática ainda seria condenável porque degrada o valor do corpo humano e do sexo ao mercantilizá-lo ${ }^{17}$.

Pode-se ver com clareza que precisamente esse ponto, nuclear no estudo de Sandel, revela seu verniz tipicamente aristotélico. Sua investigação se volta para a compreensão da natureza própria de cada bem social, visto como orientado a uma finalidade e, portanto, mediante regras e valores particulares. Apontar o mercado como meio adequado de distribuição de um bem é dizer algo sobre a natureza desse bem: é dizer que tal bem pode ser objeto de lucro e de uso. Entretanto, nem todas as coisas têm essa natureza. O próprio ser humano é o exemplo mais claro. O comércio de escravos é imoral porque coloca à venda aquilo que não pode ser comprado. Da mesma forma, não se pode estabelecer um mercado de votos ou de vagas de jurados porque a cidadania não se submete às regras da propriedade privada. Para Sandel, discutir o que pode ser ou não comprado é discutir o verdadeiro significado moral de cada bem em jogo nas interações sociais ${ }^{18}$.

Sandel não esconde que traz à arena pressupostos morais substanciais. Ele afirma expressamente que o modo adequado de distribuição de um bem é, muitas vezes, um elemento de sua essência. Sua tese não deixar de fincar raízes metafísicas: ele advoga ser um equívoco a separação entre as características naturais de um bem e o seu critério de distribuição social. São o valor e a finalidade intrínseca de algo que apontam para a sua lógica de distribuição ${ }^{19}$.

Sandel chama atenção para o fato de que existem várias formas de distribuição alheias ao mercado. Uma delas é a fila (de que falaremos mais adiante), que apela para a igualdade, mas também se somam a distribuição por mérito, por necessidade ou por sorteio. Assim, formam-se filas para se conseguir lugar para assistir a uma visita do Papa e não se admite que entre primeiro aquele que pagou mais ${ }^{20}$; as universidades admitem alunos que demonstram maior capacidade intelectual em concursos isonômicos e não aqueles que se inscrevem primeiro ou que oferecem mais dinheiro; as emergências dos hospitais priorizam pacientes segundo a gravidade de seu estado e não por ordem de chegada ou pela disposição de assinar

\footnotetext{
${ }^{17}$ Cf. id., ibid., pp. 110-112.

${ }^{18}$ Id., ibid., pp. 15-16.

${ }^{19}$ Cf. id., ibid., p. 36.

${ }^{20}$ Cf. id., ibid., p. 40.
} 
chegues polpudos; os membros de um júri são sorteados, e sua cadeira não pode ser vendida $^{21}$.

O professor de Harvard argumenta que a defesa da aplicação da lógica de mercado a tudo possui igualmente pressupostos sobre a natureza humana e sobre a vida moral, ainda que, na maioria das vezes, não explicitados, diametralmente opostos a esses que propõe. Em primeiro lugar, como já se pode perceber, os defensores do mercado adotam como princípio que a comercialização de um objeto não altera a sua natureza. Se for permitido vender sangue, o sangue continuará tendo a mesma utilidade aos que dele necessitam, e os que quiserem continuar doando seguirão praticando a mesma generosidade. Em segundo lugar, creem tais autores que o comportamento moral é uma mercadoria que se submete à lógica da escassez. A virtude humana é um recurso escasso, por isso, não podemos contar sempre com ela. $\mathrm{O}$ mercado nos poupa de depender da generosidade alheia para atingir os objetivos sociais. Se nos valemos do sistema de preços para o abastecimento de sangue, garantimos que os gestos de altruísmo não faltem e sejam direcionados eficientemente aos realmente necessitados ${ }^{22}$.

Sandel, conforme seu feitio, aplica esses princípios desenvolvidos a uma longa e aberta casuística, de modo a mostrar como a sua argumentação se concretiza na realidade. Como adiantamos, um dos mecanismos sociais diversos do mercado que ele mais explora é a ética da fila. O autor dá vários exemplos de situações em que se pode pagar para "furar" a fila ou para conseguir lugares privilegiados, desde parque de diversões e teatro comunitário até missas papais ${ }^{23}$. Segundo ele, o mercado se opõe à própria noção de fila. A ideia de receber segundo sua disposição para pagar um preço é o contrário de uma fila, regida pelo princípio de que cada um espera a sua vez. A ética da fila é a lógica da igualdade, que convida todos a abandonarem privilégios e a aguardarem a sua vez como os demais, segundo a ordem.

A estranheza causada quando alguém paga para passar à frente na fila decorre do fato de que há bens cuja natureza é mais adequada à distribuição igualitária da ordem de chegada. Ninguém espera que quem quer vender uma casa o faça à primeira oferta e não ao que aceita pagar mais, porém, igualmente bizarro seria se alguém pudesse comprar a vez num playground, no ponto de ônibus ou na fila do banheiro ${ }^{24}$. Da mesma forma, é injusto que alguém possa assistir a uma missa celebrada pelo Papa não porque ficou na fila, mas porque

\footnotetext{
${ }^{21}$ Id. ibid., pp. 43-44.

${ }^{22}$ Id., ibid., pp. 123-125.

${ }^{23}$ Cf. id., ibid., pp. 19 e ss.

${ }^{24}$ Id., ibid., p. 42.
} 
pagou para tal. Um bem religioso deixa de sê-lo se sua disposição depender da profundidade do bolso do fiel ${ }^{25}$. O grupo de teatro comunitário que executava peças de Shakespeare em praças públicas em Nova York se opôs veementemente a que os expectadores mais ricos pudessem comprar lugares na fila. Isso porque entenderam que o teatro comunitário é um patrimônio artístico da cidade e que espetáculos como esse devem fazer parte da vida do cidadão, sem possibilidade de distinção para os mais abastados economicamente ${ }^{26}$.

Sandel se volta ainda, mesmo que brevemente, para as muito polêmicas questões que envolvem a sexualidade humana e a reprodução. O caso que traz é de uma presidente de ONG dedicada a cuidar de crianças nascidas de mães viciadas em drogas que idealizou a solução de oferecer uma quantia em dinheiro para as moças viciadas que aceitassem se esterilizar. Muitos se indignaram contra essa proposta, acusando-a de configurar corrupção. Corrupção aqui se entende no exato sentido de rebaixamento da natureza do bem em jogo. Os que se opõem a essa prática creem que ela não trata a faculdade reprodutora humana com o valor que lhe é devido $^{27}$. Oferecer pagamento pela esterilização voluntária é tratar as mulheres como "máquinas danificadas de produção de bebês que podem ser desligadas por dinheiro" 28 .

Trata-se do mesmo debate levantado por outras questões em que pode haver mercantilização do corpo humano e da faculdade sexual, como a prostituição, as barrigas de aluguel e a compra de material reprodutivo. Sandel não entra nesses tópicos, mas alerta que o dilema se dá em torno de qual tipo de regras é adequado para lidar com a vida sexual e com a procriação humana: se nossa faculdade reprodutiva pode ser considerada uma propriedade nossa, sujeita ao absoluto domínio privado, ou se deve ser tida como um dom natural, que integra a nossa dignidade e se submete a um dever de cuidado que protege o seu valor intrínseco ${ }^{29}$.

Outro tema em que o professor norte-americano insiste é o do espírito cívico. Já vimos um pouco desse assunto quando falamos sobre as falhas dos incentivos. No exemplo dos pais atrasados, Sandel constata que a monetização de um dever tende a fazê-lo perder seu peso moral e desfigurá-lo em serviço ou em relação comercial. Ele nos dá mais dois casos em que os incentivos não funcionam.

\footnotetext{
${ }^{25}$ Cf. id., ibid., p. 40.

${ }^{26}$ Cf. id., ibid., pp. 25-26; 33 e ss.

${ }^{27}$ Cf. id., ibid., pp. 45-47.

28 Id., ibid., p. 48.

${ }^{29}$ Id., ibid., pp. 48-49.
} 
Primeiro, o Parlamento Suíço, desejando construir um depósito de lixo nuclear perto de uma aldeia, consultou a população da localidade num referendo. Uma pesquisa realizada pouco antes da votação mostrou que pouco mais da metade dos habitantes estava disposta a aceitar a construção do depósito, apesar dos enormes inconvenientes que causaria. Na mesma pesquisa, procurou-se alterar o cenário: e se o Parlamento propusesse o pagamento de uma indenização a cada morador como compensação? Nesse caso, o apoio à medida caiu para $25 \%{ }^{30}$.

Segundo, em Israel existe o costume do "dia da doação", em que os estudantes vão de porta em porta pedir dinheiro para causas nobres. Numa experiência, dividiram-se os estudantes em três grupos. O primeiro deles recebeu apenas um discurso sobre a importância daquela missão e partiu. Os dois outros receberam a promessa de uma recompensa monetária baseada naquilo que conseguissem arrecadar - $1 \%$ e $10 \%$, respectivamente. De fato, os que receberam $10 \%$ obtiveram mais dinheiro do que os que receberam $1 \%$, mas ambos os grupos tiveram resultados inferiores aos daqueles que nada ganharam ${ }^{31}$.

A conclusão que Sandel extrai desses casos é que a inserção do mercado em relações estranhas à sua natureza muda a forma de as pessoas as encararem e empurra para o lado o espírito cívico. Um incentivo financeiro reduz, em vez de aumentar, a disposição a aceitar um incômodo provocado pelo interesse público ou a se esforçar para chegar na hora porque o efeito de um preço oferecido não consegue se igualar ao da consciência de uma responsabilidade comunitária, corroída pela alteração da lógica para a da compra e venda. Economicamente, é ineficiente contar com pagamentos para obter da população ou de pessoas determinadas comportamentos exigidos pelo senso de dever cívico, e, moralmente, ignorar o valor de tais normas cívicas é corrompê-las e degradar o valor intrínseco das instituições comunitárias $^{32}$.

Um último ponto que nos parece apropriado destacar da análise de Sandel é sua crítica ao que chama de comercialismo. Ele fala aqui do processo de invasão de todos os cantos do espaço social pelas propagandas comerciais. Empresas compram direitos de nome e rebatizam com suas marcas estádios esportivos e estações de trem; as transmissões esportivas são tomadas por anúncios sucessivos; nos supermercados, surgem adesivos comerciais em maçãs e em bananas; romances e livros didáticos inserem marcas em suas narrativas e

\footnotetext{
${ }^{30}$ Cf. id., ibid., pp. 113-114.

${ }^{31}$ Id., ibid., pp. 116-117.

32 Id., ibid., pp. 118-119.
}

Revista Juris Poiesis - Rio de Janeiro. Vol.21-n²7, 2018, pg.70 - 94 - ISSN 2448-0517 Rio de Janeiro, 31 de dezembro de 2018. 
exercícios; casas têm seus muros pintados para servirem de outdoors; e até pessoas aceitam contratos para tatuar nomes de produtos na testa ou para colocá-los em seus filhos ${ }^{33}$.

O comercialismo, típico sintoma de uma sociedade em que tudo está à venda comenta Sandel - não derruba a finalidade das coisas. Um vagão de metrô embalado numa propaganda continua apto a transportar pessoas, assim como crianças podem perfeitamente aprender aritmética contando produtos comerciais. Contudo, o significado das relações sociais se altera pela inserção de logotipos comerciais. O sentido próprio da educação se macula quando os anúncios invadem as escolas e as salas de aula. Tatuagens que confundem o corpo humano com uma vitrine denunciam a sua reificação e a consequente perda de consideração pelo valor da pessoa. O comercialismo representa, pois, uma modalidade análoga de corrupção, em que a linguagem expressada pelos mais diversos bens sociais é atingida pelas interferências cada vez mais indiscretas das mensagens comerciais ${ }^{34}$.

Em suma, a obra de Sandel é um convite a uma reflexão profunda acerca do significado moral e das finalidades naturais de cada bem e da cada prática social, ainda que ele não chegue a encetar tal reflexão de modo sistemático. Família, amizade, sexo, educação, paisagens naturais, arte, espírito cívico, esportes, modo de encarar a morte, todos esses bens têm uma natureza peculiar, que invoca certo tipo de regras a governá-los. Somente discutindo seriamente nossas concepções acerca do valor de cada uma dessas práticas (o que significa discutir concepções do que é bom) é que poderemos tratar do lugar do mercado e de seus limites morais ${ }^{35}$. A partir dessa chave aristotélica é que Sandel ergue sua crítica à mercantilização de toda a sociedade, recordando-nos, pelos caminhos da ética, que há mais coisas em jogo nas relações sociais do que a eficiência quantificável.

\section{A ÉTICA ECONÔMICA EM MICHAEL WALZER}

Conterrâneo de Sandel, Michael Walzer também propõe uma teoria própria para a moralidade das ações econômicas, a qual, como veremos, chegará a conclusões muito semelhantes às de Sandel, mas a partir de fundamentos filosóficos substancialmente distintos.

\footnotetext{
${ }^{33}$ Cf. id., ibid., pp. 175 e ss.

${ }^{34}$ Cf. id., ibid., pp. 200-201.

${ }^{35}$ Id., ibid., p. 201.
} 
Com efeito, Walzer encontra-se no polo oposto das teorias comunitaristas, quer dizer, naquele tipo que se baseia não em Aristóteles, mas no relativismo sociológico.

O modo de filosofar de Walzer também é marcadamente diferente do de Sandel. Por um lado, enquanto Sandel, como vimos, é um pensador casuístico e propõe suas teses de modo aberto, sem preocupação de análise exaustiva, Walzer é um filósofo sistemático, e insere suas considerações sobre a ética do mercado em sua importante obra "As esferas da justiça”, na qual propõe uma teoria da justiça social. Por outro lado, conforme assinalado, se Sandel dedica uma obra unicamente ao tema da economia, Walzer trata do assunto como um dos âmbitos de sua ética política abrangente.

A teoria da justiça distributiva de Walzer, apresentada em Spheres of Justice, sustenta que os bens sociais são distribuídos em cada comunidade conforme o que chama de esferas de justiça. O mercado é uma das esferas de distribuição de bens analisadas por Walzer. Desse modo, antes de entrarmos propriamente em seus comentários sobre o tema específico, devemos reconstruir as linhas gerais de sua teoria, a partir de dois passos: i) sua definição de bens; e ii) sua explicação das esferas de justiça.

Para Walzer, antes que a sociedade possa distribuir os bens, o que ocorre é que seus membros os criam e concebem suas características essenciais. Em sua visão, os bens não têm uma natureza objetiva. São entendidos como tais a partir do consenso cultural de uma sociedade, por meio do qual lhes são atribuídos determinado valor e lógica própria de justa distribuição. Portanto, para explicar as múltiplas possibilidades distributivas, é preciso primeiramente formular uma teoria dos bens ${ }^{36}$.

Essa teoria pode ser sintetizada, segundo Walzer $^{37}$, a partir de seis proposições:

a) todos os bens com os quais a justiça distributiva está relacionada são bens sociais. Logo, não são nem podem ser valorados de modo pessoal. É verdade que alguns objetos domésticos são estimados por motivos de ordem privada ou sentimental, porém, isso ocorre somente naquelas culturas nas quais o sentimento se encontra habitualmente vinculado a tais objetos. Os bens, conclui Walzer, têm "significados compartilhados, porque a concepção e criação são processos sociais. Pela mesma razão, os bens têm significados diferentes em

\footnotetext{
${ }^{36}$ WALZER, op. cit., p. 23.

${ }^{37}$ Para uma leitura detalhada das proposições, vide WALZER, op. cit., pp. 24-27. Ver também RAMOS, Cesar Augusto. A Crítica Comunitarista de Walzer à Teoria da Justiça de John Rawls, in: FELIPE, Sônia (org.) Justiça como Eqüidade, Florianópolis, Insular, 1998, pp. 238 e 239.
} 
sociedades diferentes. A mesma 'coisa' é avaliada por motivos diversos, ou melhor, é valorizada aqui e desvalorizada ali" ${ }^{38}$;

b) homens e mulheres assumem identidades concretas em função da maneira pela qual concebem e criam - e depois possuem e utilizam - os bens sociais. As distribuições só podem ser entendidas como atos de pessoas que já têm bens especiais em mente ou nas mãos;

c) não existe um conjunto singular de bens básicos ou primários concebível para todos os universos morais e materiais, pois tal conjunto teria que ser pensado em termos tão abstratos que acabaria tendo pouca utilidade para se refletir sobre distribuições particulares. Walzer enfatiza o fato de que o próprio conjunto das necessidades, levando-se em conta tanto as morais quanto as físicas, é muito vasto, e várias são as hierarquizações possíveis. Um bem necessário como a comida, por exemplo, apresenta significados diferentes em diferentes lugares. O pão, prossegue Walzer, é "o sustento da vida, o corpo de Cristo, o símbolo dominical, o instrumento da hospitalidade e assim por diante. É concebível que haja um sentido limitado segundo o qual o primeiro daqueles significados é primordial, de modo que se houvesse vinte pessoas no mundo e pão à justa para alimentar as vinte, a primazia do pãocomo-sustento-da-vida daria um princípio distributivo suficiente. Mas essa é a única circunstância em que o faria; e mesmo aí, não poderíamos ter a certeza. Se a utilização religiosa do pão entrasse em conflito com a sua utilização nutritiva - se os deuses ordenassem que o pão fosse cozido e queimado em vez de comido - não é de modo nenhum certo qual das utilizações seria primordial" 39 . Sendo assim, Walzer se pergunta como poderíamos incluir o pão em uma pretensa lista universal;

d) é o significado dos bens que determina seu movimento. Os critérios e procedimentos distributivos são inerentes ao bem social, e não ao bem em si mesmo. Michael Walzer assevera que se compreendermos "o que é, o que significa para aqueles para os quais é um bem, compreenderemos como, por quem e por que motivo deve ser distribuído. Todas as distribuições são justas ou injustas conforme os significados sociais dos bens em causa"40. Segundo o autor, estamos aqui diante de um princípio justificativo, mas também de um princípio crítico, entendendo-se que o modo normal do discurso crítico é o apelo a princípios internos, evocados contra as usurpações praticadas por homens e mulheres poderosos. Dentro dessa lógica de raciocínio, acrescenta Walzer, quando os cristãos da Idade Média condenavam

\footnotetext{
${ }^{38}$ WALZER, op. cit., p. 25.

${ }^{39}$ Id., ibid., p. 25.

${ }^{40}$ Id., ibid., p. 26.
} 
o pecado da simonia, estavam dizendo que o significado da função eclesiástica não permitia a sua compra e venda. Obedecida a concepção cristã da função eclesiástica, "resultava daí [...] que quem exercia tal função deveria ser escolhido pela sua sabedoria e piedade e não pela sua riqueza" ${ }^{41}$. As ideias de simonia, prostituição e suborno, finaliza Walzer, se referem à compra e venda de bens que - levando-se em conta determinadas interpretações do significado que encerram - nunca deveriam ser comprados ou vendidos;

e) os significados sociais apresentam um caráter histórico. Consequentemente, as distribuições, justas ou injustas, cambiam com o tempo. É verdade que alguns bens essenciais conservam, no dizer de Walzer, estruturas normativas características, reiteradas através do tempo e do espaço. Essa reiteração, contudo, não se dá através de todo o tempo nem de todo o $\operatorname{espaço~}^{42}$

f) as distribuições devem ser autônomas quando os significados são distintos, ou seja, todo o bem social (ou conjunto de bens sociais) constitui uma esfera distributiva na qual são apropriados apenas alguns critérios e combinações. A partir deste último postulado se conclui, por exemplo, que o dinheiro é inapropriado na esfera das investiduras eclesiásticas, representando a intrusão de uma esfera em outra. Seguindo o mesmo raciocínio, a piedade não deve constituir nenhuma vantagem no âmbito do mercado, que está aberto a todos, ao contrário da igreja ${ }^{43}$.

Embora significados diferentes devam ensejar distribuições autônomas, Michael Walzer reconhece que não existe sociedade na qual os significados sociais sejam absolutamente distintos; logo, aquilo que ocorre em determinada esfera distributiva tem influência nas demais esferas. De acordo com essa lógica, o máximo que podemos almejar é uma autonomia relativa, cabendo acrescentar que Walzer vê nesta autonomia um princípio crítico $^{44}$.

\footnotetext{
${ }^{41}$ Idem.

${ }^{42}$ Idem.

${ }^{43}$ Cf. id., ibid., p. 27. A teoria dos bens de Walzer tem dois objetivos bastante claros, de acordo com Cesar Augusto Ramos: "Primeiro, ela visa criticar a concepção rawlsiana, abstrata e apriorista, dos bens primeiros (primary goods) da estrutura de base da sociedade, onde eles são distribuídos numa situação hipotética segundo um princípio de justiça também abstrato [...]. O segundo objetivo, e que deriva da crítica ao universalismo abstrato de Rawls, consiste em dizer que uma teoria política que não considera a pluralidade e o relativismo dos bens e dos critérios de distribuição desses bens, no fundo ela se distancia do ideal de uma sociedade democrática. Uma política democrática, verdadeiramente pluralista, deve admitir o caráter relativo dos bens e valores sociais. Por isso, a pretensão de prescrever um procedimento racional único em matéria de justiça contém uma contradição face à pluralidade de concepções de valores e de bens que existem nas sociedades democráticas modernas". Ver RAMOS, op. cit., p. 240.

${ }^{44}$ Cf. WALZER, op. cit., p. 27.
} 
Após admitir que as violações são de fato constantes - os bens são usurpados e as esferas invadidas por homens e mulheres poderosos -, Walzer afirma que na maior parte das sociedades, apesar da complexidade de suas combinações distributivas, existe um bem (ou um conjunto de bens) predominante, que determina o valor em todas as esferas de distribuição. Tal bem predominante é normalmente monopolizado, sendo o seu valor mantido pela força e pela coesão dos indivíduos que o possuem. Um bem é predominante, esclarece Walzer, quando seus possuidores, exatamente pelo fato de o possuírem, podem exigir uma grande variedade de outros bens. Por sua vez, continua o autor, um bem encontra-se monopolizado todas as vezes em que uma pessoa (ou um grupo de pessoas) consegue conservá-lo em seu poder diante de todos os seus rivais. Nas suas palavras:

O predomínio refere-se a um modo de utilização dos bens sociais que não é delimitado pelos seus significados intrínsecos ou que concebe esses significados à sua própria imagem. O monopólio refere-se a um modo de possuir ou controlar os bens sociais com o fim de tirar partido do seu predomínio. Quando os bens são raros e extremamente necessários como a água no deserto, o próprio monopólio os torna predominantes. A maior parte das vezes, porém, o predomínio é uma criação social mais elaborada, representando o trabalho de muitas pessoas, misturando a realidade com os símbolos. Força física, reputação familiar, cargos religiosos ou políticos, riqueza imobiliária, capital, cada um destes, em diferentes períodos históricos, foi predominante e cada um destes foi monopolizado por este ou por aquele grupo de homens e mulheres. E, seguidamente, todas as coisas boas vêm parar às mãos daqueles que têm a melhor coisa. Se possuíres esta, as outras virão em série ter contigo. Ou, mudando a metáfora, um bem predominante converte-se noutro bem e a seguir em muitos outros em conformidade com o que frequentemente se parece um processo natural, mas é de facto mágico, como que uma espécie de alquimia social. ${ }^{45}$

Em uma sociedade capitalista, afirma Walzer, o capital é o bem predominante, podendo facilmente ser convertido em prestígio e em poder. Em uma tecnocracia, por sua vez, o conhecimento técnico desempenha o papel de bem predominante, o que o torna conversível em vários outros bens. O controle monopolístico de um bem predominante, prossegue Walzer, origina uma classe dominante cujos membros estão situados no topo do sistema distributivo. Contudo, visto que o predomínio nunca é completo e o monopólio é sempre imperfeito, o domínio exercido por um grupo de homens e mulheres é necessariamente instável, sendo frequentemente ameaçado pelas pretensões de outros grupos que defendem diferentes modelos de conversão. Os conflitos sociais, assevera Walzer, estão relacionados ao problema da distribuição (a luta pelo controle dos meios de produção, por exemplo, é uma

${ }^{45}$ Id., ibid., p. 27. 
luta distributiva). É preciso reconhecer, ao mesmo tempo, que a história não nos revela a existência de um bem predominante único, de um bem que seja naturalmente predominante. De acordo com Walzer:

A pretensão de monopolizar um bem predominante - quando concebida para fins públicos - constitui uma ideologia. A sua forma normal consiste em relacionar a posse legítima com um conjunto qualquer de qualidades pessoais por meio de um princípio filosófico. Assim, a aristocracia, ou governo dos melhores, é o princípio daqueles que baseiam a sua pretensão no nascimento ou na inteligência; estes são geralmente os que monopolizam a riqueza fundiária e a reputação familiar. A supremacia divina é o princípio dos que afirmam conhecer a palavra de Deus; são os que monopolizam a graça e o cargo. A meritocracia, ou carreira aberta ao talento, é o princípio dos que afirmam ser talentosos; são os que, com mais frequência, monopolizam a educação. A livre troca é o princípio dos que estão prontos, ou dizem estar prontos, a arriscar o seu dinheiro; são os que monopolizam a riqueza mobiliária. Estes grupos - e ainda outros, semelhantemente caracterizados pelos seus princípios e haveres - competem uns com os outros, lutando pela supremacia. Ora vence um grupo, ora outro, ora se organizam coligações e a supremacia é dificilmente compartilhada. Não há nem deveria haver vitória final. Isto não quer, porém, dizer que as pretensões dos diferentes grupos sejam forçosamente erradas ou que os princípios que invocam não sejam válidos como critérios distributivos; os princípios são, com frequência, estritamente corretos dentro dos limites de uma esfera especial. As ideologias são facilmente corrompidas, mas a sua corrupção não é o seu aspecto mais interessante. ${ }^{46}$

Os conflitos sociais são conflitos de distribuição, e as lutas distributivas, no entendimento de Walzer, apresentam uma forma paradigmática, que pode ser assim sintetizada: determinado grupo de homens e mulheres (uma classe, uma casta, etc.) monopoliza um bem predominante, frequentemente convertido em muitas outras coisas. Desse modo, "os fortes apoderam-se da riqueza, os bem nascidos da alta distinção, os

\footnotetext{
${ }^{46}$ Id., ibid., p. 28.
} 
superiormente instruídos dos cargos públicos" ${ }^{\text {"4 }}$. É possível, continua Walzer, que um grande número de pessoas considere correta a ideologia que fundamenta as conversões. Contudo, sempre haverá indivíduos discordantes, questionando a justiça dos atos de conversão. Podem afirmar, por exemplo, que o grupo dominante, na verdade, não detém as qualidades que atribui a si próprio, ou ainda que os atos de conversão violam o entendimento compartilhado acerca dos bens em jogo. Uma vez estabelecido o conflito social, dentre as várias reivindicações que podem surgir, duas se destacam, merecendo maior atenção: a primeira reivindicação é no sentido da redistribuição do bem predominante, para que este seja amplamente compartilhado. Formular tal reivindicação implica dizer que o monopólio é injusto, ou seja, contesta-se o monopólio, mas não o predomínio de determinado bem social. A segunda reivindicação postula uma distribuição autônoma de todos os bens sociais, o que equivale a dizer que o predomínio, mas não o monopólio, é injusto ${ }^{48}$.

A primeira reivindicação (o monopólio é injusto) é a mais comum entre os filósofos, indo ao encontro das ideias de unidade e singularidade que caracterizam, por assim dizer, o discurso filosófico padrão. Para Walzer, no entanto, a segunda reivindicação (o predomínio é injusto) é "a que melhor exprime a pluralidade de significados sociais e a complexidade real dos sistemas distributivos" 49 .

Como se vê, a distribuição igualitária dos bens não constitui a questão mais importante para Walzer. O fundamental, isso sim, é que se tenha uma distribuição autônoma dos bens, levando em conta os seus significados sociais específicos. O autor de "As Esferas da Justiça", em suma, condena o predomínio, mas não o monopólio:

Pretendo demonstrar que nos devemos concentrar na atenuação do predomínio e não - ou não essencialmente - na destruição ou limitação do monopólio. Devemos ter em atenção o que poderiam significar o estreitamento do conjunto em que os bens especiais podem converter-se e a justificação da autonomia das esferas distributivas. Mas esta argumentação, embora historicamente não seja rara, nunca surgiu integralmente nos textos

\footnotetext{
${ }^{47}$ Id., ibid., p. 28.

${ }^{48}$ Id., ibid., p. 29. Walzer menciona ainda uma terceira reivindicação que, segundo Marx, seria o modelo das ideologias revolucionárias, com exceção, talvez, da última ideologia (ideologia proletária). Pode ser assim descrita: "a reivindicação de que um certo bem novo, monopolizado por um certo grupo novo, venha substituir o bem então predominante; isto é o mesmo que dizer que o padrão vigente de predomínio e monopólio é injusto”.

${ }^{49}$ Id., ibid., p. 30.
} 
filosóficos. Os filósofos têm propendido para criticar (ou justificar) os monopólios existentes ou emergentes, de riqueza, poder e educação. E quando não é assim, têm criticado (ou justificado) conversões específicas: de riqueza em educação ou de cargos públicos em riqueza. E tudo isto, as mais das vezes, em nome de um sistema distributivo radicalmente simplificado. A crítica do predomínio sugere, em vez disso, um modo de reformular e, seguidamente, conviver com a actual complexidade das distribuições ${ }^{50}$.

Quer dizer, a tese inicial de Walzer é que cada bem social tem uma lógica própria e em seus termos deve ser entendido e manejado. Nisso está de acordo com Sandel. Porém, ao contrário deste, não crê que os bens tenham uma natureza objetiva, mas sim que seu significado seja atribuído por cada cultura. A conclusão é que a justiça deve assegurar que a esfera de um bem não invada a dos demais, mantendo-se o acesso a cada objeto socialmente valorizado conforme as estritas normas que especificamenteo regem, e que são comunitariamente reconhecidas como aquelas mais adequadas para o bem concreto. Isso nos leva diretamente à teoria das esferas da justiça.

Em“As esferas da justiça”, Michael Walzer enumera, de modo exemplificativo, diversos bens que concebemos, criamos e distribuímos entre nós, visto que a sociedade humana é uma comunidade distributiva: a segurança e a previdência; o dinheiro e as mercadorias; os cargos públicos; o trabalho duro; o tempo livre; a educação; o parentesco e o amor; a graça divina; a consideração social; e o poder político. De acordo com Walzer, a essa multiplicidade de bens corresponde uma multiplicidade de processos, de agentes e de critérios distributivos, o que torna necessário o estudo dos bens e das distribuições em épocas e lugares diversos. Nunca houve um meio universal de trocas, assim como nunca existiu um centro único de decisões controlando a totalidade das distribuições, e nem um grupo único de agentes tomando decisões. Da mesma forma, nunca existiu um critério único que permitisse realizar todas as distribuições. Os particularismos da história e da cultura levam o autor a concluir que os bens sociais devem ser distribuídos com fundamento em razões diferentes, de acordo com processos diferentes e por agentes diversos.

Os bens, de acordo com Walzer, não têm uma natureza ou essência: são bens sociais com significados históricos. Quando os significados sociais dos bens são diferentes, as distribuições devem ser autônomas. Sendo assim, cada bem social (ou conjunto de bens)

${ }^{50}$ Id., ibid., p. 33. 
configura uma esfera ${ }^{51}$ distributiva, na qual apenas alguns critérios de distribuição são legítimos (por exemplo, a necessidade na esfera da saúde, o consentimento na esfera do poder político, etc.).

Três critérios ou princípios distributivos - livre-troca, merecimento e necessidade são comumente citados como sendo critérios gerais de distribuição. Isso, todavia, não é verdade. Ou seja, livre-troca, merecimento e necessidade, embora detenham verdadeira força, nos revelam parte da história, mas não a história toda ${ }^{52}$.

Conforme assinala Ubiratan Borges de Macedo, a livre-troca, responsável pela criação de um mercado no qual todos os bens podem ser convertidos em outros bens através do instrumento neutro do dinheiro, apresenta limitações como critério distributivo geral, uma vez que existem zonas inteiras obstruídas ao dinheiro.

O merecimento, por sua vez, também é insuficiente como critério geral de distribuição visto que, por um lado, não há um processo distributivo centralizado, ou seja, um agente central que distribua recompensas e punições por toda a sociedade; e, por outro, existem problemas técnicos para aferi-lo. Além disso, tal critério é inaplicável em diversas zonas uma vez que não serve para distribuir poder político, amor, influência, obras de arte, etc. ${ }^{53}$. Para Walzer, o merecimento "é uma pretensão sólida, mas que exige um juízo difícil e só em condições muito especiais dá lugar a distribuições específicas" ${ }^{\$ 4}$.

A necessidade, por fim, também não pode ser vislumbrada como um critério distributivo geral. Trata-se, como acentua Ubiratan, de um critério plausível para a alocação de alguns bens, contudo, é manifesta a sua insuficiência "como critério alocativo geral fora da esfera onde tem significado" ${ }^{\text {55 }}$. Walzer explicita que o referido critério não tem qualquer

\footnotetext{
${ }^{51}$ Esclarecendo o sentido metafórico do termo "esferas", Walzer escreve: “'Spheres' is a metaphor; I can 't provide a diagram nor decide upon a definitive number (my own list was never meant to be exhaustive). There isn't one social good to each sphere, or one sphere for each good. Efforts to construct a systematic account along these lines quickly produce nonsense - so quickly that even minimally generous critics ought to notice that I neither offer nor endorse any such account. Consider the easy example of food, which answers, as it were, to very different des- criptions (from which different distributions follow) in a time of extreme scarcity and in time of plenty, or at one and the same time for very poor people and for affluent people. Hence soup kitchens and food stamps on the one hand and the grocery store on the other: needs communally provided and commodities available on the market". Id., Response, in: MILLER, David e WALZER, Michael (orgs.). Pluralism, Justice and Equality, Oxford, Oxford University Press, 1995, p. 282.

${ }^{52}$ Cf. Id., As esferas da justiça..., p. 37.

${ }^{53}$ Cf. MACEDO, Ubiratan Borges de. Liberalismo X Comunitarismo na Universalidade Ética: A Crítica de Walzer a J. Rawls, in: Democracia e Direitos Humanos: Ensaios de Filosofia Prática (Política e Jurídica), Londrina, Humanidades, 2003, p. 74.

${ }^{54}$ WALZER, op. cit., p. 40.

${ }^{55}$ MACEDO, op. cit., p. 74
} 
utilidade para distribuir poder político, consideração e fama, veleiros, livros raros, etc. A famosa máxima distributiva de Marx - a cada um de acordo com as suas necessidades - é uma proposta plausível, porém totalmente incompleta. A necessidade, em síntese, dá ensejo a uma esfera distributiva autônoma, na qual ela própria configura o princípio distributivo ${ }^{56}$. Após constatar a insuficiência da livre-troca, do merecimento e da necessidade como critérios gerais de distribuição, Walzer conclui que "qualquer critério, qualquer que seja a sua força, se ajusta à regra geral [leia-se, ao princípio distributivo aberto] na sua própria esfera e não em qualquer outro lado. $\mathrm{O}$ resultado da regra é o seguinte: bens diferentes para grupos diferentes de homens e mulheres, por razões diferentes e de acordo com processos diferentes. E perceber isto bem, ou mais ou menos bem, é como que traçar o quadro completo do universo social"57.

Tendo explicitado o arcabouço teórico walzeriano, podemos encerrar detendo-nos em sua análise específica da esfera distributiva do dinheiro e do mercado. No que concerne ao dinheiro, nas palavras de Walzer, duas questões fundamentais podem ser levantadas: "o que pode comprar?" e "como é distribuído?", devendo-se enfatizar o fato de que só é possível analisar razoavelmente a distribuição do dinheiro após descrever não apenas a esfera na qual atua, como também a finalidade dessa atuação ${ }^{58}$.

Embora o preço e o valor algumas vezes coincidam, assinala Walzer, frequentemente o dinheiro não pode representar o valor: as conversões são feitas, porém, algo se perde em meio ao processo. Consequentemente, só é possível comprar e vender universalmente se os valores reais forem desprezados, na medida em que, do contrário, ou seja, se verdadeiramente levarmos em conta os valores, haverá coisas especiais que não poderemos comprar nem vender, o que implica reconhecer que "a universalidade abstracta do dinheiro é enfraquecida e limitada pela criação de valores a que se não pode facilmente pôr um preço ou a que não queremos pôr um preço" $" 59$.

Uma pesquisa empírica, assegura Walzer, nos permite verificar quais são os valores embora estes sejam objeto de frequente discussão - insuscetíveis de serem expressos em termos monetários, ou, em outras palavras, quais são as trocas monetárias bloqueadas e proibidas, isto é, convencionalmente censuradas e tidas como inadmissíveis ${ }^{60}$. O autor tem a

\footnotetext{
${ }^{56}$ Cf. WALZER, op. cit., pp. 40-41.

${ }^{57}$ Id., ibid., p. 41.

${ }^{58}$ Cf. id., ibid., p. 102.

${ }^{59}$ Id., ibid., p. 104.

${ }^{60}$ Idem.
} 
intenção de apresentar, em "As esferas da justiça", a série completa das trocas bloqueadas (intercâmbios obstruídos) nos Estados Unidos da atualidade. Embora exista a hipótese de alguma categoria essencial ter sido omitida, a lista de intercâmbios obstruídos se pretende exaustiva; de qualquer modo, a lista é extensa o suficiente para demonstrar que, se o dinheiro paga todas as coisas, muitas vezes o faz violando seus significados sociais ${ }^{61}$. A seguir reproduzimos, de acordo com o relato walzeriano, o elenco das trocas bloqueadas, que cumprem a importante finalidade de estabelecer limites ao predomínio da riqueza ${ }^{62}$ :

a) seres humanos não podem ser comprados ou vendidos, de forma que a venda de escravos (incluindo a nossa própria venda na qualidade de escravo) se encontra proibida. A liberdade pessoal também não pode ser objeto de compra e venda, embora não esteja a salvo de recrutamento ou prisão;

b) o poder político e a influência não podem ser comprados ou vendidos. Assim como os cidadãos em relação aos seus votos, as autoridades não podem negociar as suas decisões. $\mathrm{O}$ suborno constitui uma operação ilegal;

c) a justiça penal não está à venda, o que significa, em primeiro lugar, que juízes e jurados não podem ser subornados e, em segundo lugar, que os serviços dos advogados de defesa constituem matéria de provisão comunitária;

d) as liberdades de expressão, imprensa, religião e reunião independem de pagamento em dinheiro, sendo garantidas a todos os cidadãos;

e) os direitos ao casamento e à procriação não se encontram à venda. Os cidadãos, estando limitados a um cônjuge, não podem adquirir uma licença de poligamia e, se porventura houver alguma limitação ao número de filhos, não é possível admitir que tal restrição venha a ser objeto de negociação no âmbito do mercado;

f) o direito a abandonar a comunidade política não é objeto de compra e venda. Embora o Estado moderno invista nos cidadãos (o que lhe poderia conferir legitimidade para exigir a restituição de parte do investimento antes de permitir a emigração), estes podem argumentar - depreciando os benefícios da cidadania, porém captando habilmente o seu caráter consensual - que, como não haviam pedido a educação ou a assistência médica que receberam, nada devem em contrapartida. Consequentemente, o melhor é deixá-los livres para

\footnotetext{
${ }^{61}$ Cf. id., ibid., pp. 106 e 109.

62 Para uma leitura mais detalhada acerca das trocas bloqueadas examinadas pelo autor, ver id., ibid., pp. 106109.
} 
partir, desde que estejam quites com as obrigações (o serviço militar, por exemplo) que devem ser cumpridas pelos jovens que ainda não se converteram em cidadãos plenos;

g) isenções - quer se refiram ao serviço militar, à obrigação de participar em júris ou a qualquer forma de trabalho comunitariamente imposto - não podem ser vendidas pelo governo nem compradas pelos cidadãos;

h) os cargos políticos, assim como a posição profissional, não podem ser comprados. A compra dos primeiros configuraria uma espécie de simonia: a riqueza material, por si só, não revela capacidade para administrar os serviços que a comunidade política fornece aos seus membros. Por sua vez, a posição profissional, na medida em que é regulamentada pela comunidade, também não pode ser comprada; afinal, devemos ter certeza da qualificação dos médicos, advogados, etc.;

i) os serviços sociais básicos - tais como a proteção policial e a educação primária e secundária - só podem ser comprados na medida em que excederem a parcela mínima, insuscetível de compra, que deve ser garantida para cada cidadão. Obedecendo a essa lógica, os comerciantes podem contratar seguranças caso desejem obter um nível de proteção superior àquele que a comunidade política está disposta a financiar. Analogamente, os pais podem matricular seus filhos em estabelecimentos privados de ensino ou contratar professores particulares para reforçar o aprendizado. Contudo, o mercado de serviços estará sujeito a restrições, caso distorça o caráter ou diminua o valor da provisão comunitária;

j) as trocas desesperadas ou "negócios de último recurso" (trades of last resort), embora o significado do desespero esteja sempre aberto à discussão, são proibidas. Os trabalhadores, na disputa pelos empregos, não podem abrir mão do salário mínimo, da jornada de trabalho de oito horas por dia, etc., o que significa dizer que os empregos só podem ser leiloados obedecendo a certos limites. Estamos diante de uma restrição à liberdade do mercado, estabelecida em função de determinada concepção comunitária acerca da liberdade individual;

k) os prêmios e as distinções, sejam públicos ou privados, não se encontram à venda. O bom nome, ao contrário da celebridade, não está à venda;

1) a graça divina é insuscetível de compra. A venda de indulgências é inadmissível;

m) o amor e a amizade, levando-se em conta a concepção compartilhada a respeito do que significam, não podem ser comprados. Trata-se de uma venda bloqueada em decorrência da moral e da sensibilidade comuns, e não propriamente da lei; 
n) por fim, de acordo com o relato walzeriano, existe um amplo leque de vendas criminosas proibidas: assassinos não podem vender os seus serviços, não se podem vender drogas, bens roubados, produtos adulterados, informações vitais para a segurança do Estado, etc. Há ainda vendas polêmicas (armas, automóveis inseguros, remédios com determinados efeitos colaterais, e assim por diante), que nos revelam o quanto a esfera do dinheiro e das mercadorias está sujeita a uma contínua redefinição.

Estabelecido - de acordo com a interpretação de Walzer - o rol dos intercâmbios obstruídos, é necessário mencionar o que o dinheiro pode comprar e como é distribuído. $\mathrm{O}$ dinheiro, nas palavras do filósofo, tem como funções servir como medida de equivalência e como meio de troca. O mercado, que está aberto a todos aqueles que nele queiram ingressar, é o locus no qual desempenha as referidas funções. O dinheiro pode comprar "todos aqueles objectos, mercadorias, produtos e serviços, para além do que é comunitariamente fornecido, que os indivíduos acham úteis ou aprazíveis e constituem a existência normal nos bazares, lojas e entrepostos comerciais" ${ }^{33}$; esta, portanto, é a esfera na qual atua. No que concerne à distribuição, pode-se dizer, lembrando que o significado social do bem determina seu critério de justa distribuição, que o dinheiro (assim como as mercadorias) deve ser distribuído de acordo com o critério da livre-troca no mercado, isto é, de acordo com o êxito nos negócios ${ }^{64}$.

Como já havíamos salientado, Walzer é um relativista.Consequentemente, suas conclusões acerca dos limites morais do mercado se pretendem válidas de acordo com os valores consensualmente vigentes na sociedade norte-americana, ou, no máximo, nas democracias liberais contemporâneas. Trata-se, em seu ponto de vista, de observação empírica das normas de conduta vigentes na cultura do país, inaplicáveis a outras culturas, em contextos distintos.

\section{CONCLUSÃO}

Após este paralelo entre as concepções de Sandel e de Walzer no tocante à ética econômica, especificamente aos limites morais do mercado como locus próprio de distribuição de bens, somos capazes de verificar que os resultados a que chegam os autores

\footnotetext{
${ }^{63}$ Id., ibid., p. 110.

${ }^{64}$ Cf. MILLER, David. Introduction. In: Pluralism..., p. 5.
} 
são muito semelhantes. Para os dois, o mercado é uma ferramenta, em si, positiva, mas não pode ser totalizado como meio único para o estabelecimento de todas as relações da vida humana. Há bens que não são afeitos à lógica do mercado.

Apesar das conclusões praticamente idênticas, aquilo para que devemos chamar à atenção é que Sandel e Walzer possuem fundamentos filosóficos marcadamente distintos. Com efeito, ambos são comunitaristas e, portanto, entendem a ética como derivada de valores concretos de sociedades concretas (daí as respostas compartilhadas). Contudo, enquanto o primeiro baseia seu comunitarismo na noção aristotélica de bem comum e de realização plena da natureza das coisas (conforme sua finalidade), o segundo o funda num relativismo multiculturalista, em que os juízos atribuídos por consenso numa sociedade não são mais do que valores particulares, válidos enquanto persistir aquele consenso cultural.

Num quadro que aparenta concordância, temos, ao fundo, uma discordância filosófica das mais fundamentais na história do pensamento: teriam os bens sociais uma natureza objetiva, fincada na realidade, ou seriam eles meras concepções arbitrárias de indivíduos específicos, que lhe atribuem valor conforme sua educação e sua tradição?

O presente artigo, obviamente, não tem por objetivo resolver a querela entre realismo e relativismo. Não é nossa pretensão indicar qual dos dois fundamentos é o mais correto ou razoável. Para fazê-lo, seria necessário deixar de lado o temaespecífico da ética do mercado e enveredar pela metafísica.

Finalizando, podemos dizer que as respostas de Sandel e de Walzer para a questão da moralidade econômica, embora à primeira vista idênticas, revelam-se em radical dissenso no nível mais profundo dos princípios.

\section{REFERÊNCIAS}

MACEDO, Ubiratan Borges de. Liberalismo X Comunitarismo na Universalidade Ética: A Crítica de Walzer a J. Rawls, in: Democracia e Direitos Humanos: Ensaios de Filosofia Prática (Política e Jurídica), Londrina, Humanidades, 2003.

MILLER, David e WALZER, Michael (orgs.). Pluralism, Justice and Equality, Oxford, Oxford University Press, 1995.

RAMOS, Cesar Augusto. A Crítica Comunitarista de Walzer à Teoria da Justiça de John Rawls, in: FELIPE, Sônia (org.) Justiça como Eqüidade, Florianópolis, Insular, 1998. 
SANDEL, Michael J. $O$ que o dinheiro não compra: os limites morais do mercado. Trad. Clóvis Marques. - 5 ed. - Rio de Janeiro: Civilização Brasileira, 2013.

WALZER, Michael. As Esferas da Justiça. Em Defesa do Pluralismo e da Igualdade, tradução de Nuno Valadas, Lisboa, Presença, 1999. 